\title{
'Zeitoun Ennour': A new olive (Olea europaea L.) cultivar in Tunisia with high oil quality
}

\author{
Fathi Ben Amar*,a, Imen Guellaoui ${ }^{\mathrm{b}}$, Mohamed Ayadic ${ }^{\mathrm{c}}$, Olfa Elloumi ${ }^{\mathrm{a}}$, Mohamed Ali Triki ${ }^{\mathrm{a}}$ \\ and Mohsen Boubaker ${ }^{\mathrm{d}}$ \\ ${ }^{a}$ Laboratory of Improvement and Protection of Olive Genetic Resources, University of Sfax, Olive Tree Institute, Aeroport \\ road, 3000, Sfax, Tunisia \\ ${ }^{b}$ Laboratory of Improvement and Protection of Olive Genetic Resources, University of Sousse, High Agronomic Institute of \\ Chott Mariem, 4042, Sousse, Tunisia \\ ${ }^{c}$ Laboratory of sustainable olive and fruit crops in semi-arid and arid areas, University of Sfax, Olive Tree Institute, \\ Aeroport road, 3000, Sfax \\ ${ }^{d}$ High Agronomic Institute of Chott Mariem, University of Sousse, 4042, Sousse, Tunisia
}

\begin{abstract}
An olive breeding program was started in Tunisia in 1993 in order mainly to improve the fatty acid composition of the local cultivar 'Chemlali Sfax'. 'Zeitoun Ennour' is a new cultivar obtained from a cross between 'Chemlali Sfax' and the local dual-purpose use cultivar 'Chemchali Gafsa'. The morphological study of this cultivar showed that eleven characters dealing with fruit and endocarp differed from 'Chemlali Sfax', mainly regarding to their respective weights. This new cultivar had the same sensitivity to Verticillium dahliaeKleb and earlier bearing than the original variety. Its olive production was considered as high as for 'Chemlali Sfax' but with partial self-compatibility and late maturity. The new cultivar realized a net improvement in comparison with the original cultivar particularly regarding its fatty acid composition with very high oleic acid content $(>75 \%)$ and low palmitic and linoleic acid contents $(<10 \%)$. The new cultivar was recently released and will be available for growers as soon as possible.
\end{abstract}

Keywords: Chemlali Sfax, new cultivar, morphology, fatty acids, agronomy

Citation: Ben Amar, F., Guellaoui, I., Ayadi, M., Elloumi, O., Triki, M. A., Boubaker, M. (2021). 'Zeitoun Ennour': A new olive (Olea europaea L.) cultivar in Tunisia with high oil quality. Genetic Resources 2 (4), 1-6. doi: 10.46265/genresj.FIQJ8274.

(C) Copyright 2021 the Authors.

This is an open access article distributed under the terms of the Creative Commons Attribution License (CC BY 4.0), which permits unrestricted use, distribution, and reproduction in any medium, provided the original author and source are

credited.

\section{Introduction}

Attempts to develop new olive cultivars have been carried out in many olive-producing countries (Italy, Turkey, Israel, Spain, Tunisia, Egypt, Iran, China, Ukraine and Turkmenistan) as reported by Bellini et al (2008). Most of these programs have focused on crossbreeding among the most outstanding cultivars in their respective countries.

In Tunisia, a breeding program has been carried out within the context of the project 'olive breeding' (supported by the International Olive Council) since 1994. In this program, the cultivar 'Chemlali Sfax'

${ }^{*}$ Corresponding author: Fathi Ben Amar (fathibenamar@yahoo.fr) was crossed with both autochthonous and foreign olive varieties as pollen donors, yielding 1,200 seedlings. The goal of this program was to improve the acidic composition the oil, since 'Chemlali Sfax' has low oleic acid (55\%) and high palmitic acid (19.6\%) (Zarrouk et al, 2009; Bellini et al, 2008).

Several studies have shown the dietary importance of fatty acid composition of lipids. A healthy diet should contain a limited amount of saturated fatty acid (e.g. palmitic acid) to reduce the total cholesterol content and a high amount of monounsaturated fatty acid (e.g. oleic acid) which was shown to prevent the risk of cardiovascular diseases, reduce the insulin bodyrequirement and decrease the plasma concentration of glucose (D'imperio et al, 2007). According to Zarrouk et al (2009), monounsaturated fatty acids have great 
importance because of their nutritional implication and effect on the oxidative stability of oils. According to Barranco et al (2000), the low content of oleic acid for the 'Chemlali Sfax' olive cultivar is considered as a deficiency that should be resolved. High oleic acid content is also a breeding objective in sunflower (Neto et al, 2016) and peanut (Godoy et al, 2014). For example, breeding efforts in peanut have led to the release of two genotypes with much higher concentration of oleic acid (Godoy et al, 2014).

Many studies were undertaken on seedlings of the 'Chemlali Sfax' breeding program regarding morphological description (Laaribi et al, 2014; Guellaoui et al, 2019) and acidic composition of the oil (Manaï et al, 2007; Rjiba et al, 2009; Dabbou et al, 2010; Ben-Amar et al, 2019). Morphological characteristics of the 'Chemlali Sfax' olive tree seedlings showed a high genetic variability. Also, these studies revealed high variability in the main fatty acid concentrations and several seedlings had a chemical composition more interesting than that of the original cultivar.

Recently, five new cultivars obtained in the Tunisian crossbreeding program were released and published in the Official Journal of Republic of Tunisia (JORT, 2017). Two released hybrids were already reported by Guellaoui et al (2019) and Ben-Amar et al (2019). According to these authors, the two new cultivars (Zeitoun Ennwader and Chemlali Mhassen) were mainly characterized by better fatty acid composition regarding to oleic and palmitic acid contents than the original cultivar 'Chemlali Sfax'.

Regarding abiotic stresses, Elloumi et al (2016) studied the tolerance of several hybrids to salinity stress in comparison with the original cultivar 'Chemlali Sfax'.

The objective of this study was to describe the main morphological, agronomic and oil quality characters of another released olive cultivar 'Zeitoun Ennour' in comparison with the original cultivar 'Chemlali Sfax'.

\section{Material and methods}

\section{Plant material}

'Zeitoun Ennour' is a new olive (Olea europaea L.) cultivar obtained in a crossbreeding program in Tunisia. It was derived from a cross carried out in 1993/1994 between 'Chemlali Sfax' (female) and 'Chemchali Gafsa' (male), two cultivars from different geographical origins: 'Chemlali Sfax' from Sfax in the center-wast of Tunisia and 'Chamchali Gafsa' from Gafsa in the centerwest of Tunisia. 'Chemchali Gafsa' showed better fatty acid composition when compared to 'Chemlali Sfax', the most widely adopted olive cultivar in Tunisia as reported by Grati-Kamoun and Khlif (2001).

The cross was performed by pollination of flowers on bagged branches with fresh pollen grain and forced growth of seedlings was carried out in a greenhouse to shorten the juvenile period. Seedlings were planted in two open fields during 1997-1998 with a density of 1250 trees/ha ( $4 \times 2 \mathrm{~m}$ spacing): the experimental station of the Olive Institute at Sfax (Central Tunisia, lat $34^{\circ} 44^{\prime}$ $\mathrm{N}$, long $10^{\circ} 46^{\prime} \mathrm{E}$ ) and the Research Station of 'Taous', which is about $26 \mathrm{~km}$ from Sfax (lat $34^{\circ} 56^{\prime} \mathrm{N}$, long $10^{\circ}$ $\left.36^{\prime} \mathrm{E}\right)$.

The first crop was obtained in 2000 and seedling evaluation was carried out for three consecutive harvest seasons. The original seedling of 'Zeitoun Ennour' was selected mainly on the basis of its fatty acid composition. After vegetative propagation by semi-hardwood stem cuttings (2002 to 2004), propagated trees of 'Zeitoun Ennour' together with other selected seedlings were planted in a comparative trial since 2005 at $6 \times 4 \mathrm{~m}$ spacing and irrigated conditions at the experimental farm of 'Taous' in the region of Sfax.

\section{Methodology}

The evaluation of 'Zeitoun Ennour' and the check 'Chemlali Sfax' in this trial was done for three trees per cultivar during three years (2013-2015) on the following characters:

\section{Morphology}

Morphological description was carried out each year according to the procedure of IOC (International Olive Council, 1997a) by using a total of 21 characters recorded on 40 leaves (2 characters), 40 fruits (10 characters) and their endocarps ( 9 characters). One sample was taken from the productive trees each year. Leaves and fruits were harvested together when the fruit skin was almost yellow-purple and leaves were collected from the middle part of one-year old shoots.

\section{Agronomy}

Agronomic characters were recorded according to the IOC norms (International Olive Council, 1997b). Bearing earliness was determined as the number of years of the first significant bearing after planting in 2005 . This number was recorded for each cultivar when more than $50 \%$ of the plants were already in production. Olive production was evaluated on the same three trees during the three years. The olive production per tree was usually recorded in November.

The ripening index was determined according to the formula of Hermoso et al (1991) based on the colour of the skin and the pulp and varied between 0 and 7 . This index was determined on a sample of 100 fruits collected every week from November to January from the productive trees and the date which corresponded to the optimal index for harvest equal to 3.5 (International Olive Council, 1997b) was recorded.

Pollen compatibility was determined by choosing two floral branches for each tree and recording fruit sets obtained from cross-pollination (not bagged branch) and self-pollination (bagged branch). According to Barranco et al (2000), a cultivar is considered self-compatible when the two fruit set values are similar, partially self-compatible when fruit set from selfpollination is less than that from cross-pollination and self-incompatible when fruit set from self-pollination is zero. 
The tolerance test to Verticillium dahliae Kleb was undertaken in greenhouse conditions on five one year old plants per cultivar. The inoculation was made by wetting the plants in a conidial suspension adjusted to $10^{6}$ conidia/ml. Cultivars were classified into five categories according to their AUDPC average (Area Under Disease Progress Curve) established previously by Lopez-Escudero et al (2004): highly resistant (HR), 0 to $10 \%$; resistant (R), 11 to $30 \%$; moderately susceptible (MS), 31 to $50 \%$; susceptible (S), 51 to 70 $\%$; and extremely susceptible (E), 71 to $100 \%$.

\section{Fatty acid composition}

Each year, representative olive samples were harvested from the productive trees when the maturity index was approximately 3.5 (optimum maturity). Olive oil was produced by grinding $2.5 \mathrm{~kg}$ stoned olives and extracting the oil by mechanical means, following standard methods used in oil factories, including milling and malaxation. The fatty acid composition of the oils was determined by gas chromatography (GC) as fatty acid methyl esters, using a Hewlett-Packard model 4890D gas chromatograph. Fatty acids were identified by comparing their retention times with those of standard compounds. Three major fatty acids were evaluated in this study, palmitic acid (C16:0), oleic acid (C18:1) and linoleic acid (C18:2) and their concentrations in 'Zeitoun Ennour' were compared with those of the original cultivar 'Chemlali Sfax'.

\section{Data analysis}

For each morphological character, the type having the highest mean value over three years was attributed to the cultivar. Bearing earliness can be very early ( $<3$ years), early (3 years), medium (4 years), late (5 years) or very late ( $>5$ years). The ripening date corresponding to maturity index 3.5 can be in late autumn (early maturity), early winter (medium maturity) or late winter (late maturity).

Variance analysis was made for olive production and Verticillium tolerance considering years and plants as replicates respectively. For pollen compatibility, variance analysis was undertaken for each cultivar to compare fruit sets from self-pollination and free pollination considering years as replicates. For oil chemical characters, variance analysis with years as replicates was carried out for each fatty acid.

All data analyses were performed using the statistical procedures in XLSTAT 11.0 and the separation of means was done by Duncan test at $5 \%$ level.

\section{Results and discussion}

\section{Morphological characterization}

The morphological evaluation of the new cultivar is presented in Table 1 and Figure 1. Leaves of 'Zeitoun Ennour' were mostly of elliptic-lanceolate shape and flat longitudinal curvature similar to the original cultivar.

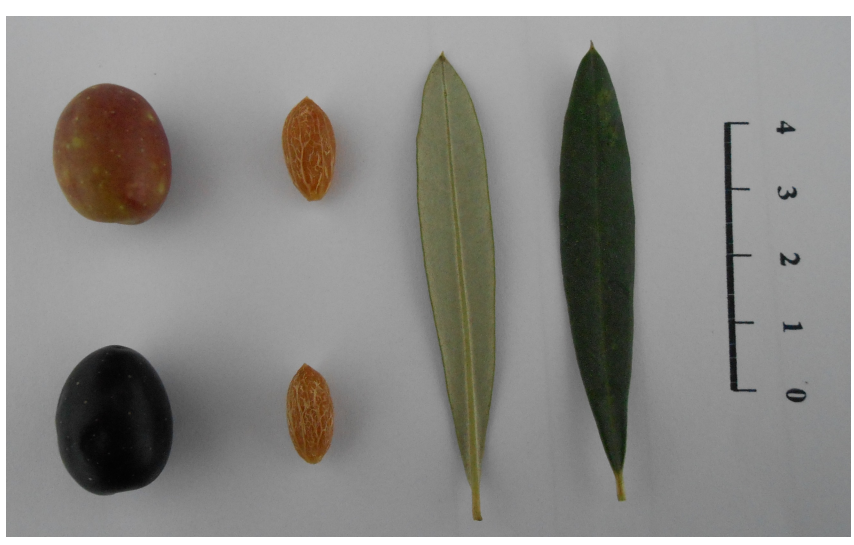

Figure 1. Leaf, fruit and endocarp of 'Zeitoun Ennour' olive cultivar. Scale in $\mathrm{cm}$.

Fruits of the new cultivar were asymmetrical, with a truncated base and rounded apex, medium weight, central maximum diameter, few lenticels, and without nipple. At maturity stage, the location of colour change start was uniformly across the whole epidermis and the colour at the end of maturity was black.

'Zeitoun Ennour' had asymmetric endocarp with medium weight, elliptic shape, a round base, pointed apex, its maximum diameter toward the apex, rugose surface and regular distribution of grooves. The apex termination was without mucro.

This cultivar differed from the typical of 'Chemlali Sfax' in more than half of the scored fruit and endocarp traits, (11 traits in total), especially regarding their respective weights, where 'Zeitoun Ennour' scored higher ( $>2 \mathrm{~g}$ and $>0.3 \mathrm{~g}$ respectively) than 'Chemlali Sfax' according to IOC norms (International Olive Council, 1997a). Chemlali Sfax was previously shown to have low fruit and endocarp weights (Barranco et al, 2000; Trigui and Msallem, 2002).

Despite the evidence of the subjectivity of the morphological description, it can be concluded that the new cultivar showed substantial genetic differences from 'Chemlali Sfax'. Laaribi et al (2014) reported wide genetic diversity observed within and between olive tree seedlings issued from the same Tunisian breeding program.

\section{Agronomic characterization}

An agronomic description of 'Zeitoun Ennour' and 'Chemlali Sfax' was carried out a the comparative field trial established at the experimental farm 'Taous' of the Olive Tree Institute (Table 2).

The new cultivar showed a short juvenility period (3 years) from planting till economic bearing. It can be classified with early bearing in comparison with 'Chemlali Sfax' (medium). Yield traits were evaluated on 10-year-old trees during the period 2013-2015, the average yield per tree was classified as high for both cultivars similar what had previously been reported for 'Chemlali Sfax' (Barranco et al, 2000; Trigui and Msallem, 2002). 
Table 1. Description of the main morphological characters of olive cultivar 'Zeitoun Ennour' compared with the control 'Chemlali Sfax'. PDM : Position of Maximum transverse Diameter

\begin{tabular}{|c|c|c|c|}
\hline Organ & Character & Zeitoun Ennour & Chemlali Sfax \\
\hline \multirow{2}{*}{ Leaf } & Shape & Elliptic-Lanceolate & Elliptic-Lanceolate \\
\hline & Longitudinal curvature & Flat & Flat \\
\hline \multirow{10}{*}{ Fruit } & Weight & Medium & Low \\
\hline & Shape & Ovoid & Ovoid \\
\hline & Symmetry & Asymmetric & Symmetric \\
\hline & PDM & Central & Central \\
\hline & Apex & Rounded & Rounded \\
\hline & Base & Truncate & Truncate \\
\hline & Nipple & Absent & Absent \\
\hline & Start of colour change & Uniform & Apex \\
\hline & Lenticels & Many & Few \\
\hline & Maturity colour & Black & Black \\
\hline \multirow{9}{*}{ Endocarp } & Weight & Medium & Low \\
\hline & Shape & Elliptic & Elliptic \\
\hline & Symmetry & Asymmetric & Symmetric \\
\hline & PDM & Toward apex & Central \\
\hline & Apex & Pointed & Rounded \\
\hline & Base & Rounded & Pointed \\
\hline & Surface & Rugose & Smooth \\
\hline & Distribution of groves & Regular & Regular \\
\hline & Apex termination & Without mucro & With mucro \\
\hline
\end{tabular}

'Zeitoun Ennour' displayed late maturity with optimum ripening period occurring in late winter while 'Chemlali Sfax' displayed medium maturity.

Regarding pollination mode, fruit set following selfpollination $(5.13 \%)$ was significantly inferior to that following crosspollination (9.87\%). Consequently, the new cultivar was found to be partially self-incompatible according to the norms of Barranco et al (2000). 'Chemlali Sfax' had a self-compatible behavior in our study since fruit sets from self-pollination and crosspollination were statistically similar (11.21 and 10.45 $\%$ respectively). The same performance was reported for 'Chemlali Sfax' by Trigui and Msallem (2002) in the centre of origin. Thus, while pollinator trees may not strictly be required in the field with this new cultivar, several pollinator trees planted in the orchards could compensate for the partial self-incompatibility, as suggested by Mehri et al (2003) in these situations. In this case, a study of the flowering period for different olive varieties is necessary to identify the best pollen donor for 'Zeitoun Ennour'.

With respect to Verticillium dahliae Kleb, our results indicated that 'Zeitoun Ennour' and 'Chemlali Sfax' had similar levels of tolerance with 65 and $57 \%$ respectively. Consequently, they were susceptible to this fungus. Thus, we suggest propagating this new cultivar with semi hardwood cuttings from healthy trees in order to avoid Verticillium infection. Morever, the best solution in the propagation of this cultivar is to follow the plant certification procedure as outlined in the EU plant health regulation (European Commission, 2016) to ensure the Verticillium free status of olive plants. In fact, Verticillium wilt is the most destructive disease affecting olive orchards in Tunisia (Gharbi et al, 2020) and in the world (López-Escudero and Mercado-Blanco, 2011).

\section{Fatty acid composition}

The 'Zeitoun Ennour' cultivar had a considerably improved fatty acid composition compared to the original cultivar 'Chemlali Sfax' (Table 3).

Table 2. Description of the main agronomic characteristics of the new olive cultivar compared with 'Chemlali Sfax'. Means for each character followed by the same letter are not significantly different except for fruit set where the comparison was made between self-pollination and cross-pollination for each cultivar.

\begin{tabular}{lll}
\hline Character & $\begin{array}{l}\text { Zeitoun } \\
\text { Ennour }\end{array}$ & $\begin{array}{l}\text { Chemlali } \\
\text { Sfax }\end{array}$ \\
\hline $\begin{array}{l}\text { Earliness of bearing } \\
\text { Olive production per tree } \\
(\mathrm{kg})\end{array}$ & $3^{b}$ & $4^{a}$ \\
Ripening & $\begin{array}{l}\text { Late winter } \\
\text { (Late) }\end{array}$ & $\begin{array}{l}\text { Early winter } \\
\text { (medium) }\end{array}$ \\
$\begin{array}{l}\text { Fruit set } \\
\text { (self-pollination) (\%) }\end{array}$ & $5.13^{b}$ & $11.21^{a}$ \\
$\begin{array}{l}\text { Fruit set } \\
\text { (cross-pollination) (\%) }\end{array}$ & $9.87^{a}$ & $10.45^{a}$ \\
$\begin{array}{l}\text { Verticillium tolerance } \\
(\%)\end{array}$ & $65^{a}$ & $57^{a}$ \\
\hline
\end{tabular}


Table 3. Mean fatty acid concentrations (\%) of the new cultivar 'Zeitoun Ennour' compared with 'Chemlali Sfax' and corresponding IOC norms (International Olive Council, 1997b). For each fatty acid, different letters following the means indicate significant differences at $5 \%$ level

\begin{tabular}{llll}
\hline Character & $\begin{array}{l}\text { Zeitoun } \\
\text { Ennour }\end{array}$ & $\begin{array}{l}\text { Chemlali } \\
\text { Sfax }\end{array}$ & IOC norm \\
\hline Oleic acid & $76.3^{a}$ & $59^{b}$ & $55-83$ \\
Palmitic acid & $10.0^{a}$ & $19.6^{b}$ & $7.5-20$ \\
Linoleic acid & $9.7^{a}$ & $16.8^{b}$ & $2.5-21$ \\
\hline
\end{tabular}

In comparison with the original variety, the mean values of 'Zeitoun Ennour' for the three fatty acids were significantly better than the original variety. The concentration of oleic acid, the main monounsaturated fatty acid, was higher for the new cultivar (76.3\%) than the original cultivar (59\%), while the level of palmitic acid, the major saturated fatty acid in olive oil, was significantly lower (10 \%) than 'Chemlali Sfax' (19.6\%). The content of linoleic acid, another important monounsaturated acid, for 'Zeitoun Ennour' was also lower (9.7\%) than 'Chemlali Sfax' (16.8\%).

In addition, the fatty acid composition of 'Zeitoun Ennour' is within the standard norms reported by the International Olive Council (1997b), while 'Chemlali Sfax' practically has the lowest value of oleic acid and the maximum limit of palmitic acid.

According to D'imperio et al (2007) and Zarrouk et al (2009), a healthy olive oil should have high oleic acid content and low palmitic acid content. Thus, we consider that the new selected cultivar 'Zeitoun Ennour' realized an important genetic gain in fatty acid composition and could be of great benefit in the Tunisian olive sector (farmers, industrials and oil exporters). From the same breeding program, two other hybrids were released and characterized. Zeitoun Ennwader (Chemlali Sfax/Lucques) and Chemlali Mhassen (Chemlali Sfax autopollinated) were presented, respectively, by Ben-Amar et al (2019) and Guellaoui et al (2019).

\section{Conclusion}

'Zeitoun Ennour' was registered by the Tunisian Ministry of Agriculture, Hydraulic resources and Fisheries (MARHP) under number 191 in January 2017 (JORT, 2017). The propagation of this new cultivar will be assured as soon as possible through a certification procedure. Simultaneously, this new cultivar is under evaluation in rain fed conditions in Tunisia.

The crossbreeding program in Tunisia since 1993 has allowed selection of superior olive genotypes which could increase the economic input of the oil sector.

\section{Acknowledgments}

The authors wish to thank the Ministry of Agriculture, Hydraulic resources and Fishery (especially IRESA) and the Ministry of Higher Education and Scientific Research (University of Sfax) for their financial support to this breeding program.

\section{Author contributions}

Imen Guellaoui performed all the measurements and notations, Fathi Ben Amar and Olfa Elloumi wrote the manuscript and processed the experimental data, Mohamed Ali Triki executed fungi tests, Mohamed Ayadi performed oil quality tests and Mohsen Boubaker supervised the work. All authors read and approved the final manuscript.

\section{Conflict of interest statement}

The authors declare no conflict of interest.

\section{References}

Barranco, D., Cimato, A., Fiorino, P., Rallo, L., Touzani, A., Castaneda, C., Serafini, F., and Trijillo, I. (2000). Catalogue mondial des variétés d'olivier (Madrid: Conseil Oléicole International), 1-360.

Bellini, E., Giordani, E., and Rosati, A. (2008). Genetic improvement of olive from clonal selection to crossbreeding programs. Advances in Horticultural Science 22(2), 73-86.

Ben-Amar, F., Guellaoui, I., Triki, M. A., Ayadi, M., and Boubaker, M. (2019). Zeitoun Ennwader - A new olive (Olea europaea L.) oil cultivar in Tunisia with high oil quality and low alternate bearing. Rev. Mar. Sci. Agron. Vét 7(4), 522-525.

Dabbou, S., Rjiba, I., Echbili, A., Gazzah, N., Mechri, B., and Hammami, M. (2010). Effect of controlled crossing on the triglyceride and fatty acid composition of virgin olive oils. Chemistry and Biodiversity 7(7), 1801-1813. doi: https://doi.org/10.1002/cbdv. 200900385

D'imperio, M., Dugo, G., Alfa, M., Mannina, L., and Segre, A. L. (2007). Statistical analysis on Sicilian olive oils. Food Chemistry 102, 956-965. doi: https: //doi.org/10.1016/j.foodchem.2006.03.003

Elloumi, O., Regaieg, I., Lehiani, M. A., Amar, F. B., and Chaari, A. (2016). Salt tolerance of new olive varieties issued from a Tunisian breeding crosses. Journal of New Sciences 15, 1303-1311.

European Commission (2016). Regulation (EU) 2016/2031 of the European Parliament of the Council of 26 October 2016 on protective measures against pests of plants. url: http://data.europa.eu/eli/reg/ 2016/2031/2019-12-14.

Gharbi, Y., Bouazizi, E., Cheffi, M., Amar, F. B., and Triki, M. A. (2020). Investigation of soil-borne fungi, causal agents of olive trees wilt and dieback in Tunisia. Archives of Phytopathology and Plant Protection .

Godoy, I. J., Santos, J. F. D., Carvalho, C. R. L. D., Michelotto, M. D., Bolonhezi, D., Freitas, R. S. D., Kasai, F. S., Ticelli, M., Finoto, E. L., and Martins, A. L. M. (2014). IAC OL 3 and IAC OL 4: new Brazilian peanut cultivars with the high oleic trait. Crop Breeding and Applied Biotechnology 14, 200-203. doi: https://doi.org/10.1590/1984-70332014v14n3a30 
Grati-Kamoun, N. and Khlif, M. (2001). Caractérisation technologique des variétés d'olivier cultivées en Tunisie. Ezzaitouna special number, 1-74.

Guellaoui, I., Amar, F. B., Ayadi, M., and Boubaker, M. (2019). Chemometric classification of new Olea europaea L. cultivars developed through a crossbreeding program in Tunisia. Journal of Scientific Agriculture 3, 22-27. doi: https://doi.org/10.25081/ jsa.2019.v3.5453

Hermoso, M., Uceda, M., Garcia-Ortiz, A., Morales, J., Frias, L., and Fernández, A. (1991). Elaboración de aceite de oliva de calidad volume 5/91 of Colección: Apuntes. (Sevilla: Dirección General de Investigación, Tecnología y Formación Agroalimentaria y Pesquera), 36-39.

International Olive Council (1997a). Methodology for primary characterization of olive varieties. Project RESGEN-CT (67/97).

International Olive Council (1997b). Methodology for secondary characterization of olive varieties. Project RESGEN-CT (67/97).

JORT (2017). List of protected varieties object of the plant variety certificates for the year 2016. Official Journal of Republic of Tunisia, 033, 25.04.2017.

Laaribi, I., Mezghani-Aiachi, M., and Mars, M. (2014). Phenotypic diversity of some olive tree progenies issued from a Tunisian breeding program. European Scientific Journal 10(6), 292-313. doi: https://doi. org/10.19044/esj.2014.v10n6p\%25p

López-Escudero, F. J. and Mercado-Blanco, J. (2011). Verticillium wilt of olive: a case study to implement an integrated strategy to control a soil-borne pathogen. Plant Soil 344, 1-50. doi: https://doi.org/10.1007/ s11104-010-0629-2

Lopez-Escudero, F. J., Rio, C. D., Caballero, J. M., and Blanco-Lopez, M. A. (2004). Evaluation of olive cultivars for resistance to Verticillium dahliae. Eur. J. Plant. Pathol 110, 79-85. doi: https://doi.org/10. 1023/B:EJPP.0000010150.08098.2d

Manaï, H., Mahjoub-Haddada, F., Trigui, A., Daoud, D., and Zarrouk, M. (2007). Compositional quality of virgin olive oil from two new Tunisian cultivars obtained through controlled crossings. Journal of the Science of Food and Agriculture 87(4), 600-606. doi: https://doi.org/10.1002/jsfa.2732

Mehri, H., Mehri-Kamoun, R., Msallem, M., Faîdi, A., and Polts, V. (2003). Reproductive behaviour of six olive cultivars as pollenizer of the self-incompatible olive cultivar Meski. Adv. Hort. Sci 17(1), 42-46. doi: http://doi.org/10.1400/14142

Neto, A. R., Oliveira, R. D., Miguel, A. M., Mourad, A. L., Henriques, E. A., and Alves, R. M. V. (2016). Environmental effect on sunflower oil quality. Crop Breeding and Applied Biotechnology 16, 197-204. doi: https://doi.org/10.1590/1984-70332016v16n3a30

Rjiba, I., Debbou, S., Gazzah, N., Chreif, I., and Hammami, M. (2009). Profiles of volatile compounds from nine new hybrids obtained by controlled crossings on olive 'Chemlali' cultivar and mediterranean vari- eties. Natural Product Research 23(7), 622-632. doi: https://doi.org/10.1080/14786410802155939

Trigui, A. and Msallem, M. (2002). "Oliviers de Tunisie," Catalogue des Varietés Autochtones et Types Locaux volume 1 (Ministère de l'Agriculture, IRESA, Institut de l'Olivier, République Tunisienne), 159p.

Zarrouk, W., Baccouri, B., Taamalli, W., Trigui, A., Daoud, D., and Zarrouk, M. (2009). Oil fatty acid composition of eighteen Mediterranean olive varieties cultivated under the arid conditions of Boughrara (southern Tunisia). Grasas y aceites 60, 498-506. doi: https://doi.org/10.3989/gya.021109 